\title{
WHITMAN'S IMPOSSIBLE MOTHER
}

\author{
STEVEn A. Wartofsky
}

Perhaps i should begin by addressing the problem of my title; who is Whitman's Mother? Or rather, what is it I intend to discuss that I have given the name, "Mother"? The simplest answer to that question is the biographical one; one could describe Louisa Whitman, or better yet, explain what Whitman thought of his mother: "All through middle age," he says, "I thought my heredity stamp was mainly decidedly from my mother's side . . . she was strangely knowing. She excelled in narrative-had great mimetic power; she could tell stories, impersonate; she was very eloquent in the utterance of noble moral axioms - was very original in her manner, her style."1 In Specimen Days, Walt makes a point of mentioning, while describing his genealogy, that his mother's family were great horse-breeders, and says of Louisa, "My mother, as a young woman, was a daily and daring rider."2 The emphasis in both texts is on the mother as the type of innate, native energy that Whitman repeatedly claimed as part of the explanation of his own identity. We wonder, whether as the "utterer of noble, moral axioms" Louisa had more to say than the usual conventionalisms-or whether Whitman felt the need to make these claims about his mother to sustain and authorize the rhetoric of his own authenticity, an authenticity which men seem frequently to imagine is somehow grounded in humble gestures toward the maternal. Certainly Louisa Whitman the daring rider of horses supplements the figure of the fleshy, sensual persona of "Song of $\mathrm{My}$ self." It would be reasonable, in other words, for us to suspect the picture of Louisa Whitman which Walt gives to us.

Louisa Whitman was not the voracious reader Walt was, and her personal letters to Walt reveal little commitment to the norms of grammar, spelling and punctuation of her time or ours. ${ }^{3}$ She was, in other words, not part of the minority of the population at that period who could claim to be highly literate. But at least according to Walt's reports, she was nonetheless literally an influential "voice" for his imagination. Walt thinks of her as a strong oral creator, an excellent storyteller; most of his family fails to appear with any distinctness in his poetry, but in an important passage from "The Sleepers" Louisa appears specifically in the guise of the storyteller narrating, and thereby authorizing, a homosexual encounter:

Now what my mother told me one day as we sat at dinner together,

Of when she was a nearly grown girl living home with her parents on the old homestead. 
A red squaw came one breakfast-time to the old homestead,

On her back she carried a bundle of rushes for rush-bottoming chairs;

Her hair, straight, shiny, coarse, black, profuse, half-envelop'd her face,

Her step was free and elastic, and her voice sounded exquisitely as she spoke.

My mother look'd in delight and amazement at the stranger,

She look'd at the beauty of her tall-borne face and full and pliant limbs,

The more she look'd upon her she loved her,

Never before had she seen such wonderful beauty and purity,

She made her sit on a bench by the jamb of the fireplace, she cook'd food for her,

She had no work to give her, but she gave her remembrance and fondness.

The red squaw staid all the forenoon, and toward the middle of the afternoon she went away,

O my mother was loth to have her go away,

All the week she thought of her, she watch'd for her many a month,

She remember'd her many a winter and many a summer,

But the red squaw never came nor was heard of there again. ${ }^{4}$

The mother's desire for the squaw is obviously idealized here, but think of the situating of the tale; it is an event that occurs when Louisa is a "nearly grown girl living with her parents on the old homestead." Combine this with Walt's assertion that his mother was an "utterer of noble moral axioms," and we can see that this tale might easily be imagined as being meant for Walt, the nearly grown young man living with his mother, wondering about the legitimacy of his homosexual desire.

And think also of the red squaw: the last detail is that her voice sounds exquisitely as she speaks. Like the mother, she is described as a woman with primitive power and beauty, whose power is most explicit for Walt in the sound of her voice. And then we remember mention in "Song of Myself" of the pure contralto singing in the organ loft, and we think also of the end of Section 26 of the same poem:

I hear the train'd soprano (what work with hers is this?)

The orchestra whirls me wider than Uranus flies,

It wrenches such ardors from me I did not know I possess'd them,

It sails me, I dab with bare feet, they are lick'd by the indolent waves,

I am cut by bitter and angry hail, I lose my breath,

Steep'd amid honey'd morphine, my windpipe throttled in fakes of death,

At length let up again to feel the puzzle of puzzles,

And that we call Being. $(L G, 56)$

Hearing the trained soprano, Walt asks, is my work, is my voice, of a piece with hers-"what work with hers is this"-and this question initiates a passage which Harold Bloom identifies, I think correctly, as a rather explicit depiction of masturbation and male orgasm. ${ }^{5}$ Note the care which Whitman takes to prevent us from making the mistake of 
assuming it is the soprano's voice which stimulates this self-seduction; rather, he imagines her singing as a public, autoerotic act which opens a space for his own autoerotic writing.

So who is Whitman's biographical Mother? In the poetry and in Whitman's autobiography, at least, she is the Self who by her own revelations legitimates Whitman's homosexual identity. This legitimation derives explicitly from Whitman's attribution of power to the mother's speaking being; it is as a speaking being that she gives the possibility of identity (and sexuality) to her son. When the poet sings in his own voice, he is at certain moments, therefore, ventriloquizing the voice of the mother.

This is who Louisa Whitman is for Walt, and that is my first point; we cannot think of biography, of personal history, as anything other than the reading of the subject for partial ends. There is no more an "essential" Louisa than there is an "essential" Walt Whitman. We might accuse Whitman of inexactness in the fabrication of his own genealogy; evidence we have indicates that much of what Whitman says about himself and his own past in his writings is at worst made up, and at best translated into what will fit most effectively into the framework of the public image he took such pains to construct throughout his career. But that inexactness is honest insofar as its consistency is revelatory of the intensity of the poet's self-construction. It is meant to lead us away from the traces of the writer's life which have not been subjected to his will; it is a transcendentalizing impulse consistent with the impulse motivating Whitman's desire to imagine a whole Self, a Self whose every component is suffused with the consistent will-or voiceof its author.

The Mother Whitman wants to imagine in his work, then, would in some fundamental sense not be Other. The Other, in Whitman's writing, is the name for another voice - the patriarchal voice, explicitly the voice of the orator, as I have argued elsewhere. This is an Other which Whitman wants simultaneously to identify with and to negate. For if the voice of the Other with a capital "O"-which Lacan at one point in his thinking identifies as the realm of the Symbolic, the realm of organized, rationalized language, the place where the pressures of the unconscious are sublimated into the formations of collective discourse-if that voice is one which Whitman sees as the source of public, institutional power in his culture (which it would certainly seem to be, given the popular successes of Webster, Clay, Calhoun, in one generation, and Emerson, Henry Ward Beecher, and Theodore Parker in the next), it is also a voice whose power Whitman feels is repressive of something essential to his own identity, namely, his homosexuality. ${ }^{7}$

Within this identity, Whitman imagines the community truly authenticating his own voice as being a community of women, of those 
whose speaking is public and powerful but ambivalent when it comes to the celebration of their ability to speak for others. Whitman's mother can speak for Whitman's self only by speaking from within the terms of her own experience. She may be the "utterer of noble, moral axioms" but those axioms are clearly not prescriptive, if we can take the story of the red squaw as a representative example; they are efforts to provide access to the mother's own, private experience as the means of enabling the identity of another. The contralto sings within the organ loft, the soprano sings only after much training; in these cases, each female voice sings inside the terms of the Symbolic order, i.e., within the rationalized structures where singing is permitted; but that singing nevertheless exceeds the limits of the order within which it is allowed to take place. ${ }^{8}$ And that surplus of voice which cannot be contained within or represented by the boundaries of known discourse becomes the central object of the poet's desire in "Song of Myself":

Loafe with me on the grass, loose the stop from your throat, Not words, not music or rhyme I want, not custom or lecture, not even the best, Only the lull I like, the hum of your valvèd voice. ( $L G, 32-33$ )

The lull, the hum, exist separately from the forms within which they are contained: words, music, rhyme, custom, lecture. They survive the rationalization, the stops, their Other. This voice is the Mother as other to the Other; as the alternative transcendental locus from which Walt Whitman can speak his own being. But the words "lull," "hum," if we are to be rigorous about it, cannot ultimately convey this sense of voice freed completely from articulation. If voice-as opposed to writing-is considered as in some sense a less institutionalized representation of the self, as the imagined immediacy of a self which has not gone through the structurings of written discourse, then voice without meaning is obviously more primitive, more primary, still.

The imagined Mother's voice-the voice heard before the formalizations of a particular language provide the limits which help to form the sounds appropriate to it-precedes all articulation, is presented as the root of identity, of communication, which Whitman is attempting to make reference to in this passage. It is ultimately an unimaginable voice, because to imagine it is to bring it already into contact with the realm of language, to differentiate it as self constituted within the structures of an always already present institutionalization. ${ }^{9}$

This unimaginable voice is also the voice of the perfect sexual partner in "Song of Myself"; its enunciation is followed by the following familiar passage:

I mind how once we lay such a transparent summer morning,

How you settled your head athwart my hips and gently turn'd over upon me, 
And parted the shirt from my bosom-bone, and plunged your tongue to my bare-stript heart,

And reach'd till you felt my beard, and reach'd till you held my feet. $(L G, 33)$

On the one hand, sexually explicit; on the other, physiologically and even metaphorically almost unimaginable. If we simply read this as spirit mystically fusing itself with matter, as a purely spiritual union of soul with body, then we wonder in what sense it would be possible to imagine spirit's settling its head athwart Walt's hips. If we try to imagine the persona here as female, we must take pause when considering the beard. If this is a representation of oral sex between homosexual men, the easiest reading of the passage, the one difficulty lies in trying to imagine the tongue plunged to the barestript heart.

The agent of desire is represented metonymically in the image of the tongue, and this I think is the crucial fact about the passage: the disembodied tongue becomes the source of desire, of self-knowledge, of identity; it formulates the poet's body for us, strips it bare and spreads it out. But the tongue itself has no place, no visible body to which it is clearly connected. It is the origin, in many senses, of the self represented in the poem; but its own origin, its own location within the body, is occluded. I would like to call this the Mother's tongue situated outside the cultural body, a tongue given no place in the body its speaking brings into being except insofar as its speaking produces being. The Mother's tongue speaks through Whitman, but what it says is inevitably articulated in the language of the Other, as evidenced by the passage of "Song of Myself" which follows the sexual moment just discussed:

Swiftly arose and spread around me the peace and joy and knowledge that pass all the argument of the earth,

And I know that the hand of God is the promise of my own,

And I know that the spirit of God is the brother of my own,

And that all the men ever born are also my brothers, and the women my sisters and

lovers,

And that a kelson of the creation is love,

And limitless are leaves stiff or drooping in the fields,

And brown ants in the little wells beneath them,

And mossy scabs of the wormfence, heap'd stones, elder, mullein and poke-weed.

This encounter with the tongue infuses the poet's being with a vision couched within the biblical language and conventions of mystic revelation. But there is a clear hierarchy present in this vision, with the hand and spirit of God at the top, the brothers next, the sisters after them. The tongue gives Whitman access to knowledge, but it is now access to a knowledge of the patriarchal Other, a knowledge which displaces the more immediate knowledge present in the hum of the voice. As is also the case with Emerson's transparent eyeball, here vision has displaced 
the organ which conceives it; we could go so far as to say that the vision is an explicit repression of the tongue which enabled it.

Does this repression of the Mother's tongue seem inevitable in Whitman's work? I would like to turn now to a poem crucial to my reading of Whitman, "As I Ebb'd with the Ocean of Life." My argument is that in this poem, Whitman comes closer than he does anywhere else in his work to re-situating the original speaking voice-the voice of the Mother-in a body disjunct from the cultural body to which it has been attached in the language of revelation we've just observed. It is re-embodied, is given a place within language that is nonetheless also imaginable as outside the language of the Symbolic order of discourse. ${ }^{10}$

That body is, of course, the ocean of "As I Ebb'd with the Ocean of Life." It is by now a familiar truth of Romanticism that Nature serves as the margin within which the nineteenth-century poets of nature find a voice capable of arguing with the language they inherit. It is alternately an aristocratic voice speaking out against the incursions of a middle class celebrating its new-found economic and technological power, and a revolutionary voice speaking for resistance to the destructive totalizations which power has become freshly capable of. The point we can make from our current perspective is that what formerly seemed a realm of revolutionary possibilities, in language, in philosophy, has become for us a sign of the extent to which difference has been colonized by culture. I won't go into this larger issue except to say that no reference today can be made to the natural that isn't imbued with the cultural use of the idea of the natural as that which culture imagines as its particular outside. Nature is no longer ever really culture's Mother; when it takes its own course, as it did for instance in Yellowstone National Park a few years ago, we can no longer even say that it has taken its own course; perhaps the fires in Yellowstone were the result of changes in the atmosphere people have induced, and we argue that perhaps we shouldn't let nature take its own course, to more perfectly preserve the illusion of nature as a beautiful place, a place we can resort to when we've had enough of ourselves. Nature must be like the good mother of object relations theory in order for us to be willing to sustain its difference. When it rebels against that image, demands for immediate action against its destructive power become popular. ${ }^{11}$

One question I'm trying to raise with all this is, is it possible any longer to conceive of the ocean as Whitman might have imagined it? Do we have any sense left of the limitlessness and powerfulness of a nature immune to cultural agency, a nature fundamentally unintelligible, fundamentally alien to cultural experience? Of a mother's tongue which isn't always already imbued with the crystalline formations imposed on it by the Other? Because without this sense, it becomes impossible to conceive of the stretch of the imagination Whitman asks us to make in 
"As I Ebb'd" when he describes the ocean as a fierce old mother crying endlessly for her castaways:

As I ebb'd with the ocean of life,

As I wended the shores I know,

As I walk'd where the ripples continually wash you Paumanok,

Where they rustle up hoarse and sibilant,

Where the fierce old mother endlessly cries for her castaways,

I musing late in the autumn day, gazing off southward,

Held by this electric self out of the pride of which I utter poems,

Was seiz'd by the spirit that trails in the lines underfoot.

The rim, the sediment that stands for all the water and all the land of the globe.

$(L G, 253-254)$

The expansion of self imagined in the passages of "Song of Myself" discussed earlier led to identification with the voice of the Father; here, however, in a poem which has been generally taken as a sign of Whitman's anxieties over the success of his poetic endeavours, there is an essential paradox in the assertion of the first line. The poet's ebb is, through identification with the ebb of the ocean, in fact also an expansion in the presence of another. The Mother is the primitive other here, and she is no longer the pure, seductive tongue; she plays a game of release and absorption with her "castaways" in the poem, and Whitman finds alternating comfort and frustration in the dual possibilities of fusion and rejection held out as promise and threat by this untranslatable figure of power. The small self, seized again by a spirit, is shaken from his center this time by the seizure.

In Psychoanalysis Never Lets Go, François Roustang makes the argument in the chapter "The Game of the Other" that the relationship between analyst and patient is constituted by a continual doubling of each one's image back on the other:

Such is the analyst's force that the patient's attempts to bring the other into his game resemble the struggles of a gnat against an elephant. The patient then falls into a more or less embryonic state and assumes the role of the son before the sadistic father of the primitive horde, or of the child before the all-powerful mother. He can never succeed in reversing the roles and thus in revealing the specificity of the game, and this leads to an endless process of unbeing in which the diminished patient enacts his part in the pleasure of annihilation.

At the opposite extreme, the patient thinks only of devouring the analyst. Absorption will indeed occur, but without any results, because the analyst will attempt the impossible task of finding any independence whatsoever, and he will remain paralyzed.

In another case, the analyst is an old hand at analysis and is always quite invulnerable. The patient cannot make the right moves in order to get the game started because the distance to the analyst is simply too great. Nothing happens, and this impasse can last for years.

On the other hand, the patient's obsessional and perverse defenses might be so effective that he never risks lowering his guard. His need of the other's nonexistence is 
conveyed only through repeated complaints, a form of demand in which one is so little engaged that one's true nature and reasoning never appear. ${ }^{12}$

Two repetitions of the same alternation: either the analyst is imagined as overly powerful, and the patient responds either by playing a game of self-diminution or by simply not being able to comprehend at all; or the patient imagines himself the all-powerful one, and the analyst enters for him the realm of non-being either through failure to assert his otherness or simply through paralysis. These two either-or situations, in which communication between patient and analyst is blocked because the extremes of powerful and annihilated or paralyzed self becomes unbreachable, are situations Roustang's work is dedicated to overcoming, so that constitution of the self via therapy can become something more than a re-insertion of the individual ego back into the discourse of the normative Other.

I make reference in this digression to Roustang's transferential analytical situation because I think Whitman engages in a related critique of this problem in "As I Ebb'd." Now this is not to simply say that I am about to insert Whitman's poem into an already established psychoanalytic discourse, as radical as that discourse might be; I remain convinced that such operations subsume the more literary concerns I'm intrinsically interested in under the concerns of another discipline. I prefer using psychoanalytic theory strictly as supplement to the reading of the text being constructed here. ${ }^{13}$ We have been looking at the problem of the mother's voice, voice conceived as that which in one way or another seems invariably to end up being repressed by being translated into the discourse of the Other, the mystic vision couched in the language and parallelisms of the Bible, the authority of the self being predicated on reference to a mother figure whose presence is at the same time repressed by its translation into the voice of the patriarchal Other. Remember, we haven't discussed Louisa Whitman except insofar as she has been produced by Walt's writing. To my mind, it's no coincidence that this problem of the mother's tongue should be very much like the problem of the subject Roustang is addressing in the psychoanalytic primal scene of transference.

Psychoanalysis, even in its most rarefied metapsychoanalytic form, is specifically the historical discourse which investigates, critiques, and perpetuates the problem of individual identity as constituted within European and American culture since the eighteenth century. If that identity has formed itself within this culture specifically through the silencing of the voice of the feminine, a voice which it has systematically sought to exclude from the precincts of its own culture, then it can be said that psychoanalytic discourse is an investigation of this repression, even when in the worst case it seems intent on silencing the voice it had intended to listen to-in other words, in Dora's case ${ }^{14}$ Lacan's revolu- 
tion is based in part on his resistance to the idea of psychoanalysis as a process whose main goal is to re-introduce the marginalized subject into the normative terms of collective discourse-i.e., the idea of psychoanalysis as a means of reinforcing the process of repression which is its subject-and this revolution is being re-considered in the writings of Roustang, Kristeva, and others whose work is a critical revision of Lacanian theory. ${ }^{15}$ Whitman's conceptual revolution, when it occurs (and part of what I've been arguing is that it tends to relapse into the processes of repression that it is trying to undo), involves a critical repudiation of the transcendental position he is usually taken as the simple proponent of.

The first step of this revolution has been Whitman's refusal to merely inherit and inhabit the rhetorical conventions of public self provided by the culture as the normative collective discourse within which both individual and collective identity can be articulated. This step takes place in the attempts I have already outlined to imagine the female voice as independent of the cultural terms within which it inevitably becomes situated.

The more important step, which takes place in "As I Ebb'd with the Ocean of Life," is to attempt to imagine this voice in a place where it is empowered without being either simply idealized or invariably translated. What I want to avoid is precisely the location of female identity as simply that which is outside culture, as "nature." 16 Jacqueline Rose states the dilemma quite clearly in Sexuality in the Field of Vision:

... what happens to this maternally connoted and primitive semiotic is that it is first defined as the hidden underside of culture (we can recognise the proximity of this to the classical demonic image of femininity) and then idealised as something whose value and exuberance the culture cannot manage and has therefore had to repress (a simple reverse of that first image which makes femininity the ideal excluded instance of all culture). ${ }^{17}$

This semiotic is what I have been discussing, the mother's tongue as primal voice, primitive voice, voice without the coupures essential to language. This is partially what Kristeva's work on the semiotic has examined, namely the possibility of referring to the surplus that exceeds the rationalizing, meaning-oriented functioning of language; a surplus that nevertheless is central to the constitution of discourse. ${ }^{18}$ Rose's point is that designation of this surplus, this voice, as the outside of culture, as resistant, for instance, to the transcendental gesture, to the language of philosophy, leads straight back to the denial of the participation of the feminine within the forms of language and culture designated by Lacan's idea of the Symbolic order.

Without going into the extensive analysis of "As I Ebb'd" that I have developed elsewhere, I will point out only that in this poem 
Whitman negates the very same self which he has imagined in his work up to this point as the representative, transcendental American Self:

O baffled, balk'd, bent to the very earth,

Oppress'd with myself that I have dared to open my mouth,

Aware now that amid all that blab whose echoes recoil upon me I have not once had the least idea who or what I am,

But that before all my arrogant poems the real Me stands yet untouch'd, untold, altogether unreach'd,

Withdrawn far, mocking me with mock-congratulatory signs and bows,

With peals of distant ironical laughter at every word I have written,

Pointing in silence to these songs, and then to the sand beneath. (LG, 254)

The "real Me," like the ocean in this poem, becomes one of a series of figures for what exceeds the already written; by pointing to the writing, and then to the sand, the "real Me" indicates the impossibility of authenticating one's self by asserting its origin in the semiotic, in this excess of self which perpetually escapes explanation. This "real $\mathrm{Me}$ " is Whitman's analyst, the one whom Roustang in his four-fold description of the sources of analytical failure calls the all-powerful, all-knowing analyst, whose presence seems to enable at best dreams of selfannihilation on the part of the patient. By imagining its power, Whitman also imagines his own silencing. The voice of the patient becomes a complaint, a complaint based on the realization that the fusion of self and voice it had taken for granted is a fake.

But it is the undoing of this complaint which is the task of "As I Ebb'd"; the fact that by the end of the poem Whitman does not choose merely to return to the voice of the absorbing Self, the voice of his earlier work, leaves us with the sense that the either/or of the failed dialogue of self with world, patient with analyst, has been overcome. The concluding stanza of the poem reveals an acceptance of the mother's independent voice, the mother's acts of self-reproduction in her manipulation of the fragments tossed between herself and the island Paumanok, which doesn't have to include the poet's own abjection as its inevitable complement:

Ebb, ocean of life, (the flow will return,)

Cease not your moaning you fierce old mother,

Endlessly cry for your castaways, but fear not, deny not me,

Rustle not up so hoarse and angry against my feet as I touch you or gather from you.

$(L G, 255)$

The poet can now accept the mother's voice in its fierceness instead of merely in its idealization; the absolute continuity between the mother's tongue and Whitman's own, which earlier seemed essential to Whitman's envisioning his own originality, is no longer necessary. She can 
speak her own desire, her own capacity to absorb; she no longer needs to be spoken for through the poet's own voice, no longer needs to be translated into a language whose form denies the truth of her substance.

But that's the catch: the fierce old mother never really says anything in "As I Ebb'd with the Ocean of Life"; she moans, she cries. Yes, I can argue that her voice does not undergo the translation I've been speaking of as characteristic of the earlier poetry; but isn't she thereby excluded from the realm of the Other as completely as she would be in the sublimation of her voice? The mother-ocean in the poem, in other words, is again presented as yet another form of that primitive semiotic, that voice preceding language. It remains a problem.

\section{Loyola University, Chicago}

\section{NOTES}

1 Horace Traubel, With Walt Whitman in Camden (1908, rpt. New York: Rowman and Littlefield, 1961), 1:113-114.

2 Floyd Stovall, ed., Prose Works 1892 (New York: New York University Press, 1963), $1: 8$.

3 See Edwin Haviland Miller, ed., The Correspondence (New York: New York University Press, 1961), 1:8.

4 Harold W. Blodgett and Sculley Bradley, eds., Leaves of Grass, Comprehensive Reader's Edition (New York: New York University Press, 1965), 429-430. All further references are to this edition, abbreviated $L G$.

5 Harold Bloom Agon (New York: Oxford University Press, 1982), Chapter 7.

6 The Crisis of the Whole: National and Personal Identity in Walt Whitman's Poetry, 1855-1865. (Ph.D. dissertation, DAI 49/11A, 3364).

7 For Lacan's discussion of the Other and the Symbolic, see Ecrits (New York: W.W. Norton, 1977).

8 Lacan, 195-198.

$9 \mathrm{I}$ am indebted in my thinking about voice and poetry to John Vernon, The Poetry of the Body (Urbana: University of Illinois Press, 1979); Victor Feld, Sound and Sentiment (Philadelphia: University of Pennsylvania Press, 1982); and Julia Kristeva, Desire in Language (New York: Columbia University Press, 1980).

10 To put it very simply, the Symbolic Order in Lancanian theory is the place where the Real and the Imaginary collide, via the mediations of language. This is the place, in more common parlance, where the negotiations between self and other, self and world, mind and thing, take place.

11 The basic language of "good" and "bad" objects in the splitting of the mother is originally part of Melanie Klein's work on object relations. See Hanna Segal, Introduction to the Work of Melanie Klein (New York: Basic Books, 1974), 92-102, for a useful overview of this idea. 
12 Francois Roustang, Psychoanalysis Never Lets Go (Baltimore: Johns Hopkins University Press, 1983), 98.

13 Stephen Black's work, for instance, though perhaps more conventionally rigorous in psychoanalytic interpretation than my own, strikes me as resulting in an understanding of Whitman's work which serves only to confirm the validity of the psychoanalytic schema. See Stephen Black, Whitman's fourneys Into Chaos (Princeton: Princeton University Press, 1975). The persistent importance of Edwin Haviland Miller's Walt Whitman: A Psychological Fourney (New York: New York University Press, 1968), by contrast, is due to the extent his reading interprets psychoanalytic thinking and schemas as much as it does the literary text the schemas are brought to bear on. Though Miller's work relies upon an older construction of Freudian and psychoanalytic theory than my own, I still consider it a model for the ways in which this kind of interdisciplinarity can function to open up, rather than excessively schematize, the interpretive experience.

14 Sigmund Freud, Dora; the most definitive collection of essays discussing Freud's famous text on female hysteria is probably In Dora's Case: Freud-Hysteria-Feminism (New York: Columbia University Press, 1985).

15 See also Shoshana Felman, Facques Lacan and the Adventure of Insight: Psychoanalysis in Contemporary Culture (Cambridge: Harvard University Press, 1987) for further analysis of this issue.

16 Luce Iragaray's work remains the touchstone for the concept of feminine voice and self as something existentially marginal to all forms of normative linguistic, political and psychoanalytic structures. See Iragaray, This Sex Which is Not One (Ithaca: Cornell University Press, 1985).

17 Jacqueline Rose, Sexuality in the Field of Vision (London: Verso Books, 1986), 154.

18 See Julia Kristeva, Desire in Language, Chapters 5-6. 